\title{
Newspapers' Treatment of Child Abuse Cases in Lahore
}

\author{
Mudasser Ahmad Tahir ${ }^{1, *}$
}

\begin{abstract}
According to research, the careless use of words in news coverage on child abuse has been brought to light. It was discovered that the language used in the crime story has a significant impact on reducing the severity of the crime and, as a result, has a substantial impact on how the readers perceive the nature of such crimes. The purpose of this research was to conduct a detailed investigation on how incidences of child abuse are reported in Pakistani media. Its primary emphasis is on understanding how news articles about child abuse are framed and promoted in the media. The reports of child sexual abuse that appeared in four daily newspapers (two English and two Urdu) between January 2016 and January 2018 were studied for the frames and language used to convey the events. A summary of the results was presented in the form of graphs and tables. To get an accurate count, we surveyed a total of 2718 people across both English-language and Urdu-language newspapers. According to this study, a total of 706 cases of child sexual abuse were reported in Lahore during the years (2016-2010) and 355 cases of CSA (Child Sexual Abuse) were reported in Lahore during the years (2010-2010). How the newspapers covered the news about child abuse did and does have a sound impact in underlining the importance of this matter on both the governmental and public scale. Sensitized coverage is problematic because it tends to portray child abuse more as a political issue than as a grim reality, affecting everyone across society. It is time to strictly implement anti-child abuse lawes so that crimes against children could be effectively prevented.
\end{abstract}

Keywords: Child Abuse, Newspaper Treatment, Framing, and Priming.

${ }^{1}$ Department of Mass Communication, Lahore Leads University, Lahore, Punjab, Pakistan.

* Corresponding Author: mudi.ahmad111@gmail.com 


\section{Introduction}

The legal definition of Child Sexual Abuse (CSA) is described as how an adult, or an older child sexually exploits a child. Sexual abuse of a child may occur via the use of strangers or someone the child knows. When the abuser is the child's relative through blood or bylaws, 'incest.' This includes a variety of aspects of the crime, e.g., Voyeurism (getting sexual satisfaction from looking at a child naked), Exhibitionism (exposing one's sexual parts), Exposing a baby to pornography_using a child for prostitution or pornography. Sexually suggestive kissing or touching a child.

World Health Organization (WHO) defines CSA broadly, along with the International Society for Prevention

Child Abuse and Neglect, as " the involvement of a child in sexual activity that he or she does not fully comprehend, is unable to give informed consent to or for which the child is not developmentally prepared, or else that violates the laws or social taboos of society. Children can be sexually abused by adults or other children who are by their age or stage of development in a position of responsibility, trust or power over the victim" (WHO, 2006). Any country's future depends on its children. The development of a child is crucial. It has also been firmly established that the country is responsible for assisting the child in achieving its potential. The nation must allow the child to reach their full potential.

According to the latest statistics, in Pakistan (Sahil, 2020), the number of instances of child sexual abuse in the first half of 2020 has risen quickly. By an average of six children, 53 percent were females, and 47 percent were females. According to the study, most instances recorded were in Punjab- $57 \%$. Sindh accounted for $32 \%$ of the remainder and Khyber Pakhtunkhwa for $6 \%$. Consequently, estimates of the 3,832 incidents of child sexual assault recorded in 2018 have not been taken into consideration, and these numbers do not account for a significant number of unreported instances of child sexual abuse and humiliation.

Media often in the framing. newspapers' elder abuse coverage? One of the methods for constructing social problems is through framing. Problems, causes, and solutions to social issues are all defined by frames. The process of influencing an individual's ideas of meaning attached to communications is known as framing (Gitlin, 1980). To assist the audience in better grasping the events they are reporting, journalists employ frames. By stressing certain parts of events or situations and connecting them, framing theory aims to identify how the news media impact public opinion (Scheufele, 1999; Entman, 1993). Various groups, including reporters and advocacy organizations, can influence how an issue is framed, which impacts the public's perception of how it should be handled (Gamson \& Modigliani, 1989).

In recent years there has been an upsurge in the number of child abuse cases publicized in the media. The growing incidence of child sexual abuse has received international attention. On the surface, most people do not sense that their local newspaper is a crucial supply they depend upon for local information. Press reportage helped break the CSA's quiet, raised the voice of victims, stirred up a local, national, and international response, and paved the way for criminal prosecutions and prosecutions. Furthermore, not all CSA coverage in the media is currently credible. According to communication studies, the media's coverage of CSA is often erroneous. An intervention time-series analysis and a statistical correlation method were used to estimate both the number of child abuse complaints and the number of newspaper stories about them. 
The media may set the agenda for the most important problems to the public by selecting daily items to report (McCombs, 2004). For journalists, framing a story in a specific manner may help shape the audience's perception of the subject matter (Druckman, 2011). Framing a problem is valuable in many ways, but it may also be harmful if the issue is presented in a manner that does not accurately represent the reality of the subject matter (Aubrun \& Grady, 2003). Although a considerable number of newspaper firms have openly ignored the relevant norms and codes of behavior, they nevertheless disclose the names of victims of sex crimes, particularly children, although they are forbidden to do so by the law. The increase in the reporting of instances of sexual crimes has revealed the lack of training and the sensitivity of media people and organizations on the relevant legislation.

Substantial communication between the many institutions involved, and especially the system of particular CSA legislation, forceful policymaking, and interference in contrast to preventive measures. Depending on their age or stage, adults or other children can abuse children sexually if they have authority, control, or responsibility for them. Unfortunately, in Pakistan, such crimes are not reported by the parents/guardians of the victims due to undue shame and stigma attached to them. The study's goal was to look at how newspapers in Pakistan reported on news articles involving child sexual abuse. A Quantitative method of Content analysis was used to analyze the framing of CSA news stories in four popular Newspapers in English and Urdu language published between the years 2016-2020.

The specific objectives of this research area: a) To examine the frequency in the child sexual abuse news stories by the newspaper. b) To analyze the framing of the child sexual abuse stories. c) To compare the framing of English and Urdu Newspaper.

\section{Literature Review}

Child safety is a difficult topic to quantify since societal norms, norms, and attitudes are fundamentally subjective and socially created. Statistics on child protection problems are accessible globally, including in Pakistan. Consequently, it aims to introduce a problem to the public's notice and put it on policy agendas, systematic proof of the problem's incidence and prevalence is required. The majority of people think that publicizing horror tales about children has aided in the societal acceptance of abuse, the passage of legislation, and the establishment of institutes with more effective systems for identifying and safeguarding maltreated children (American Humane Association 2006; Franklin \& Parton, 1991; Johnson, 1995; Watkins 1990).

Children are not to be exploited or mistreated, nor are they to be discarded like broken toys. Children should be protected from those who want to harm them as responsible adults as they are the backbone of our community. Furthermore, there has been historical controversy about the mere notion of child abuse (CA) not to mention child sex abuse (CSA). The elements of children misuse have been perceived as a worldwide arising social issue that is exceptionally connected with child embarrassment. It's being viewed as a major social issue and the primary driver for the enduring of numerous individuals' is a new wonder and surprisingly that too in certain nations and settings in particular.

As a significant part of children in need of protection have no access to services because no one has informed the authorities of their predicament, this accelerated screening may be very beneficial. This may be an extreme issue in society. children are manner ahead for the 
country and children face violence and statutory offense through their people. in large part, a defendant is from a loved one or close relative or friend. Child abuse causes more than one problem for nations and communities. The scientific and mental outcomes are extraordinarily obvious. Victims cannot carry out as conventional contributors to society.

This media coverage is based on exercises in news insurance and journalists' and publishers' goals and practices. To recognize this, it is extremely important to analyze the information methods collected by the media and to remember the strategies used to inform the press agenda via prevalent ideologies (including their link between the assets and rituals of "daily production of news." As a result, the media have a beneficial impact on the broader public, which child safety may leverage to keep the public informed. More monitoring of the abused children and the suffering families led to a greater understanding and a role for the media (Hoefnagels \& Mudde, 2000).

Press reportage helped break the CSA's quiet, raised the voice of victims, stirred up an international, national and local response, and made it easier for people to be prosecuted for crimes. Furthermore, not all CSA coverage in the media is currently credible. The media's coverage of CSA is often erroneous, according to communication studies. A better understanding of the CSA and its values will allow you to make improvements to public health within that context. You should also examine how the media may affect public opinion as it relates to the CSA. As a method to investigate media impact, communications academics developed the belief in framing in combination with the agenda-setting theory. Frames are "principles of selection, emphasis, and presentation composed of tacit theories about what exists, what happens, and what matters" (Gitlin,1980).

The process of identifying societal issues through framing plays an important role, "selecting and highlighting some facets of events or issues and making connections among them to promote a particular interpretation, evaluation, and/or solution" (Entman, 1993), This shows how individuals should consider and deal with problems (Gamson \& Modigliani, 1989). In the 2009 Meta-Study by the University of Barcelona published by the Clinical Psychology Review, 65 studies were analyzed from 22 countries to estimate the "overall international figure" for child sexual abuse as a result of their relative abuse, entitled "The prevalence of child sexual abuse in the community and student samples: a meta-analysis."

The following are some of the results of the research:

1. A worldwide estimate of $7.9 \%$ of males and $19.7 \%$ of females suffered sexual abuse before 18.

2. Males were affected at $7.5 \%$, while females were affected at a rate of $25.3 \%$.

3. In terms of geography, Africa has the highest rate of child sexual abuse $(34.4 \%)$. Europe's prevalence rate was the lowest (9.2\%). Prevalence percentages ranged from 10.1\% to 23.9\% between America and Asia.

Who is responsible for sexually abusing children? Victims of abuse may be coworkers, neighbors, or relatives. In homes, schools, mosques, churches of the Mosques and leisure centers, young sports rallies, and other children's meetings, some sexually abused children. In essence, abusers may and often are a variety of youngsters. The report states (Characteristics of crimes against juveniles. Durham, NH: Crimes against Children Research Center), Approximately $90 \%$ of children victimized by sexual assault recognize their abusers. A stranger abuse just 10\% of children sexually assaulted. Their families molest roughly $30 \%$ of sexually abused children. The abuser is more likely to be a family member if the victim is 
young. Family members made about $50 \%$ of those who molested a child under six. Of the abused youngsters aged 12 to 17 years, 23\% were family members (Snyder, 2000). Family members molest about $60 \%$ of sexually abused children.

In his research, Swain (2014) explores that the children out of a home are needed to protect their rights. The legislation about the children must be done in four steps; the first step should be about the jurisdiction, the second about the rules, regulations, punishment and, employment, the third about concerns on the parents to live together for the welfare of children, and the fourth step before the children with disabilities. Long-time journalist Richard Cohen wrote an op-ed in the Washington Post in 1984 titled "The new anxiety over child abuse." Cohen's op-ed questioned whether the prevalence of child abuse was growing or if society was now paying attention to it. According to him, families with two incomes are more likely to feel stress, and he suggests that this stress may be a contributing factor to child abuse. Cohen concludes: "instead of solving a problem, we simply preach an ethic of overreach in which people are told they should be able to do it all -- and that failure, of course, is their fault." While his opinion piece is not a premonition of the issue we still have today, it does signal that we as a culture must assume responsibility for how we react to child abuse if it occurs.

\subsection{Newspaper Framing the CSA Stories}

The media is a medium via which public knowledge of responsibilities and rights may be spread. It may empower the public about their basic rights and oblige the government to protect those fundamental rights. The newspaper covers just a tiny fraction of all abuse and neglect in child abuse cases. The events described are often sensationalized or may have disastrous results, like death or injury. The media generally concentrate on distinctive, unusual, or distressing instances when they cover child abuse (Aldridge, 1994; Saint-Jacques et al., 2010). Considering the assumption that child welfare agencies often intervene in carelessness and public awareness of domestic violence, this kind of media coverage creates a skewed picture of abuse. Many social problems, like child abuse, may be framed in such a manner as to impact how people think about and react to the situation, and this is especially true when it comes to complicated social issues like this one. A broad range of concerns have been investigated in the past, but only lately has the framing of child abuse begun to get significant attention. Researchers Aubrun \& Grady (2003) looked at 120 newspaper articles and a slew of TV documentaries to find the keyframes used in tales concerning child maltreatment. A list of those frames, along with a short explanation, is given below:

a) Failure of child protective services: Attempting to protect children from abuse cannot be trusted when bureaucratic organizations and incompetent caseworkers are involved b) Sexual predators: "Stranger danger" is reinforced because perpetrators are not family members. c) The confusing line between discipline and abuse: Determine whether or not a parent has passed the difficulty to define the line between punishment and abuse may be challenging. d) The sanctity of the family: Families' parenting decisions should be respected while children must be protected by organizations responding to abuse. It is difficult for reporters to put child abuse in a broader perspective because it is less fascinating to speak about the complex circumstances that lead to abuse or neglect (e.g., parenting knowledge, the family's social or economic position), and it is more difficult for reporters to put child abuse in a broader context because of the difficulty in doing so. 
The theoretical structure of this study has been founded on the idea of the researcher's judgment. In the affiliation, one theory is used as the theoretical arrangement of the study.

\subsection{Newspaper Framing Theory of Child Sexual Abuse (CSA)}

The framework refers to a social phenomenon's social construction, typically by mass media sources, political and social movements, political leaders, or other players and organizations. It is a process of selective impact on the perception of the individual's significance ascribed to words and sentences. It is usually classified as either frame in thinking or a frame in communication. Frames in thought are mental representations, interpretations, and simplifications of reality. Frames in communication are the exchange of frames between various actors.

In the scientific literature, a critical assessment of CSA reporting was noticed with more and more standards for reporters that offer suggestions and rules for the more significant CSA reporting. The purpose of these practical recommendations for CSA media coverage is to provide journalists a hand regarding the subject. These rules are issued by various journalist associations, government bodies, and non-governmental organizations (e.g., DART Centre for Journalism and Trauma, 2007; National Human Rights Commission of India (NHRC), 2004).

It's important to note that the media only covers a tiny percentage of child abuse and neglect instances. The incidents covered are often sensationalized and may result in catastrophic consequences such as injury or death. The news media significantly influences child sexual abuse (CSA) practice, legislation, and public image. The mix of political, social, cultural, and economic factors impacts public health, and the media is used to promote public and politicians' debates about public health problems in particular (Wallack et al., 1993).

\section{Application of theory in Current Study}

The researcher used this theory to cover the effects of news stories covered by the newspaper regarding child sexual abuse issues. The complete theory specializes in how readers pursue newspaper stories and how comfortable they may be with their form, substance, and mode of use. We may classify readers the use of this principle primarily based totally on their level of interaction in assessment to the regions of facts and also Individualize facts retrieval framework for them as well.

\section{Research Methodology}

I wanted to investigate the treatment of newspapers how the newspaper framing the news stories of child sexual abuse cases in Lahore. I explored the cases in Lahore, which will better understand the treatment of newspapers regarding child sexual abuse cases in our living society. In this research study, the content analysis research method was used. The research tool was created for the aim of the study to discover answers to the research question. This research tool was validated with the help of social science expert. The research, too, was modified according to his advice. The data was gathered using the research tool developed for the study. The content analysis was used to look at sampling news articles from The News (English), Dawn (English), Daily Duniya (Urdu), and Daily Express (Urdu) newspapers to analyze the nature of child sexual violence reports in news journals. In this context, the news media are used. Two of the newspapers are in English and two are in Urdu. 
To identify and evaluate the topics of the news items, content analysis has been employed to give an insight into respective sound patterns and news frameworks that are generally used by journalists in each country. This study is based on exploring the relationship between readers and newspaper stories regarding child sexual abuse issues in our society. Among terms of knowledge of sexual and child abuse problems in children in Lahore, the print media (newspaper) plays a significant role. Lahore is the provincial capital city and 2nd largest city in the country. Both the English and Urdu versions of the national daily newspapers were used to gather the data. The journals were chosen based on their reputation and accessibility. Two English newspapers and two URDU newspapers were chosen for this study's purposes. The selected newspapers are: The Nation, Dawn, Daily Duniya, and Daily Express.

\section{Results}

The newspaper review for the analysis of child abuse cases reported in newspapers. In dallies published between the years (2016-2020). Additionally, research was conducted in 2021. The newspapers were chosen depending on a lot of factors, including their national reach and circulation. The researcher looked through all newspapers and wrote news articles and detailed news and tried to find out about the treatment of children's sexual abuse. The materials were then categorized into larger categories based on research questions depending on the kind of incident. Then, for each newspaper and in total, items in each category were tallied. In addition, each topic was explored in detail in these articles on the framing of the stories of child sexual abuse, the aim of reporting, and the extent of child welfare concerns.

Table 1: Total Number of Child Sexual Abuse cases reported in Lahore newspapers during (Years 2016-2020)

\begin{tabular}{cccc}
\hline Year & Cases in Punjab & Cases in Lahore & Percentage \\
\hline 2020 & 1707 & 82 & 4.80 \\
2019 & 1502 & 98 & 6.52 \\
2018 & 2403 & 148 & 6.16 \\
2017 & 2168 & 112 & 5.17 \\
2016 & 2676 & 266 & 9.94 \\
\hline
\end{tabular}

Table 1 showed that 266 cases were reported in Lahore in the year 2016 which is the highest number. In the year 2018, the second-highest number of 148 cases was reported. 112 cases were reported in Lahore during the year 2017, 98 cases were reported in the year 2019 and in the end, 82 cases were reported in Lahore during the year 2020.

Table 2: Total Number of CSA reports in Lahore newspapers (Years 2016-20)

\begin{tabular}{ccc}
\hline Year & Lahore Cases & CSA cases in Lahore \\
\hline 2020 & 82 & 51 \\
2019 & 98 & 56 \\
& & \\
2018 & 148 & 89 \\
2017 & 112 & 42 \\
2016 & 266 & 117 \\
\hline
\end{tabular}


Table 2 showed that in 2016 was 266 highest number of cases of CSA were reported in Lahore. 89 cases of CSA were reported during the year 2018, 56 cases were found in 2019, 51 cases were found in year 2020, and the lowest 42 cases were reported in year 2017.

Table 3: Summary of newspapers reporting of child Sexual issues in Lahore (2016-2020)

\begin{tabular}{cccccc}
\hline $\begin{array}{c}\text { Name } \\
\text { Newspaper }\end{array}$ & Language & Area & $\begin{array}{c}\text { Total No. of } \\
\text { Cases Report }\end{array}$ & $\begin{array}{c}\text { Child Sexual } \\
\text { Abuse Cases }\end{array}$ & Others \\
\hline The Nation & English & Nationwide & 690 & 355 & 135 \\
Dawn & English & Nationwide & 678 & 340 & 149 \\
Daily Duniya & Urdu & Nationwide & 700 & 350 & 145 \\
Daily Express & Urdu & Nationwide & 650 & 338 & 114 \\
\hline
\end{tabular}

Table 3 shows that in the past five years, from (2016-2020) there are 2718 cases of child abuse cases in Lahore were reported in four newspapers (2 English and 2 Urdu). Data is shown in the above table. Five years analysis shows that in Lahore, 2178 child abuse cases were reported in national newspapers, which included both English and Urdu. The researcher took 2 English newspapers (The Nation News and Dawn News) Urdu newspapers (Daily Duniya and Daily Express). The English Newspapers (The Nation and Dawn) had reported a total of 1368 cases included 695 cases of CSA, as we saw that Urdu Newspapers (Daily Duniya and Daily Express) had reported 1350 cases which included 680 cases of CSA.

\section{Discussion}

Sexual assault is growing increasingly common in the middle, working, and poor communities, both in urban and rural locations. The news reports also tended to show that these reports do not find any cause for murdering and killing children. In newspapers, the news relevant to child protection issues was not getting attention as it should be. Because the media has their agenda and their priority agenda is political issues. The newspaper did not get stories on the front pages until any specific case got attention on social media or mainstream media. There is no take care code of ethics regarding publishing or framing a story about child sexual abuse.

Framing is mostly defined as selecting and promoting certain aspects of perceived reality through the promotion of a certain problem definition, causal interpretation, moral evaluation, or recommendation for treatment, or as a distinction between aspects of an object or attributes that characterize the feature of an object and are the central theme of a specific message (S. D. Reese, 2001; McCombs \& Ghanem, 2001; Entman, 2004). The query supports framing - the problem is linked with the media and affects how advertising is viewed. The findings showed that total of 17,222 cases of Child Abuse were reported in Pakistan in newspapers during the past five years (2016-2020). Total 10,456 cases of Child Abuse were reported in Punjab during the five years (2016-2020). Total 706 cases were reported in Lahore only during the years (2016-2020). Total 355 cases of CSA (Child Sexual Abuse) were reported in Lahore during the years (2016-2020). Total 51 cases of CSA report in Lahore during the year 2020. Total 56 cases of CSA report in Lahore during the year 2019. Total 89 cases of CSA report in Lahore during the year 2018. Total 42 cases of CSA report in Lahore during the year 2017. Total 117 cases of CSA report in Lahore during the year 2016. 


\section{Conclusion and Future Directions}

In Pakistani society, the newspaper coverage emphasizes children's actual and prospective dangers. The role of a newspaper provides a sound methodological justification as the record of child abuse issues in Pakistan, especially in Lahore, which is 2nd largest city in the country. The newspaper's coverage underlines the importance of print media in putting problems related to child abuse in public and on governmental agendas. The increase in reporting instances of sexual crimes has revealed the lack of training and the sensitivity of media people and organizations on the relevant legislation - understanding how print media (newspaper) frame the news stories regarding child abuse. It seems clear that sensationalized coverage has contributed to the increasing politicization of child abuse, often expressed through calls for inquiries, which in turn have contributed to our systems becoming riskaverse and punitive in their orientation. Altogether, the results of this study can help child welfare professionals understand how child abuse is portrayed to the public and help media professionals understand ways in which those portrayals could be improved. Child sexual abuse may be reduced in the nation by enacting strong anti-child sexual abuse legislation. In addition, educational initiatives may assist mainstream child sexual abuse to raise societal awareness of the subject.

The most pressing thing while moving forward with reporting cases related to child abuse is that data must be collected, processed, and displayed with utmost accuracy. The reports of child abuse cases could provide a solid ground for the kind of agenda/policy making is required. Print Media (Newspaper) ensures the code of ethics for reporting child abuse issues. Print Media (Newspaper) should ensure the privacy of the victim and their family members. Names and pictures should be hidden. Child-friendly treatment of child abuse issues should be established. Child-friendly journalism must be practiced in the publication of reports or news stories. There is no doubt that newspapers have a vital role in raising awareness regarding child abuse issues in society. However, the reporting will only be meaningful if they get attention from relevant government institutions and civil society members. By looking at the type of reporting that gets done on the issue of child abuse, it would be safe to conclude that this coverage offers us significant insights regarding the nature and scope of abuse, kidnappings, and exploitation of children in Pakistan. We will have to identify from this the structural and institutional deficiency that could have contributed to the suffering of children.

\section{References}

Aubrun, A., \& Grady, J. (2003). How the news frames child maltreatment: Unintended consequences. Prevent Child Abuse America. Retrieved from http://www.preventchildabuse.org/about_us/reframing/downloads/analysis.pdf

Entman, R. M. (1993). Framing: Toward Clarification of a Fractured Paradigm. Journal of Communication, 43(4), 53-69.

Molotch, H. (2004). Review, Robert Entman, Projections of Power: Framing News, Public Opinion and US Foreign Policy. American Journal of Sociology, 110(3), 833-834.

Levitt, C., \& Gitlin, T. (1981). The Whole World Is Watching”: Mass Media in the Making and Unmaking of the New Left. Labour / Le Travail, 8/9(1), 420-438. 
Gamson, W. A., \& Modigliani, A. (1989). Media discourse and public opinion on nuclear power: A constructionist approach. American Journal of Sociology, 95(1), 1-37.

Goddard, C., \& Saunders, B. J. (2000). The role of the media. Child Sexual Abuse in Queensland: Selected Research Papers, 75-130.

Gross, K., \& D'Ambrosio, L. (2004). Framing emotional response. Political Psychology, 25(1), $1-29$.

Hoefnagels, C., \& Mudde, A. (2000). Mass media and disclosures of child abuse in the perspective of secondary prevention: putting ideas into practice. Child Abuse $\S^{\circ}$ Neglect, 24(8), 1091-1101.

Snyder, H. N. (2010). Sexual assault of young children as reported to law enforcement: Victim, incident, and offender characteristics. DIANE Publishing.

Swain, S. (2014). History of child protection legislation. Royal Commission into Institutional Response to Child Sexual Abuse. Sydney

Wallack, L., Dorfman, L., Jernigan, D., \& Themba-Nixon, M. (1993). Media advocacy and public health: Power for prevention. Sage.

Wallack, L., \& Dorfman, L. (1996). Media advocacy: A strategy for advancing policy and promoting health. Health Education $\mathcal{E}^{2}$ Behavior, 23(3), 293-317.s

Organization, W. H. (2006). Preventing child maltreatment : a guide to taking action and generating evidence. In apps.who.int. World Health Organization.

Wallack, L., Dorfman, L., Jernigan, D., \& Themba-Nixon, M. (1993). Media advocacy and public health: Power for prevention. Sage.

Woolley, J. T. (2000). Using media-based data in studies of politics. American Journal of Political Science, 44(1), 156 